\title{
Ayak ve ayak bileğinde tuzak nöropatileri
}

\author{
Foot and ankle entrapment neuropathies
}

\author{
Kaya H. Akan ${ }^{1}$, Koray Ünay ${ }^{2}$ \\ ${ }^{1}$ Gebze Medical Park Hastanesi, Kadıköy, İstanbul \\ ${ }^{2}$ Özel Medivia Hastanesi, Çengelköy, İstanbul
}

\begin{abstract}
Alt ekstremite tuzak nöropatileri, çok sık görülmeyen ve bu nedenle tanısı atlanan veya zor olan hastalıklardır. Periferik sinirlerin anatomisinin ve olası tuzak bölgelerinin bilinmesi çok önemlidir. Tanının konulmasında, ayrıntılı fizik muayene ve görüntüleme yöntemlerinin kullanılması da büyük rol oynar. Doğru tanı konulmasını takiben, tedavide dış baskıların azaltılması, inflamasyonun dindirilmesi, neden olan ayak ve ayak bileği deformitelerinin düzeltilmesi ve sıkıştıran yumuşak dokuların gevşetilmesi gerekir. Bu derlemede, alt ekstremitede en sık rastlanan tuzak nöropatilerinin oluş mekanizmaları, patofizyolojileri, tanısal yöntemleri ve tedavileri sistematik bir yaklaşımla incelenmektedir.
\end{abstract}

Anahtar sözcülkler: ayak ve ayak bileği; sinir; tuzaklanma; nöropati

\begin{abstract}
Lower extremity neuropathies are infrequent and therefore they are usually underdiagnosed or undiagnosed entities. The knowledge of peripheral nerve anatomy and possible entrapment sites is an issue with utmost importance. A detailed physical examination and radiologic studies are also valuable in the diagnostic pathway. After the correct diagnosis, one should focus on diminishing external pressure, inflammation, correction of the causative deformities and pinching soft tissues. This review gives a systematic approach to the anatomy, patophysiology, diagnostic methods and the treatment of most commonly encountered nerve entrapments in the lower extremities.
\end{abstract}

Key words: oot and ankle; nerve entrapment; neuropathy

dallarına ayrılır. Plantar sinir, ayağın plantar kısmının intrensek motor fonksiyonu ve duyusunu sağlar. Anteromediyalde safen sinir, safen ven ile birlikte seyreder ve ayak bileğinin dorsomediyali ile orta ayağın duyusunu verir. Derin peroneal sinir, tibialis anterior arteri ile birlikte ayak bileği retinakulumu arkasında, ekstansör hallusis longus (EHL) ile ekstansör dijitorum longus tendonu arasından derin tabakaya iner; ekstansör dijitorum brevise motor bir dal, 1. ve 2. parmaklar arasındaki dokuya da duyu dalı verir. Yüzeyel peroneal sinir, derin fasyayı, fibulanın ucunun yaklaşık 8-12 cm üstünde anterolateral fasyadan terk eder ve ayağın başparmağının mediyal kısmından, lateralde 4 . ve 5. parmaklara kadar dorsumunun duyusunu veren mediyal ve intermediat kutanöz dallarına ayrılır. Sural sinir, gastroknemius kasının üzerinde, bacağın yaklaşık ortasında derin aponevrozu terk ederek, kısa safen sinir ile birlikte Aşil tendonunun lateralinden seyreder. Topuğun lateral kısmının ve 5. metatars ile 5. parmağın lateral kısmının duyusunu verir. ${ }^{[2]}$

- Illetişim adresi: Doç. Dr. Kaya H. Akan, Gebze Medical Park Hastanesi, Ihlamur Sk. No:18/39 Göztepe, Kadıköy, İstanbul Tel: 0532 - 2529300 e-posta: akan44@yahoo.com

- Geliş tarihi: 13 Ekim $2015 \quad$ Kabul tarihi: 13 Ekim 2015 


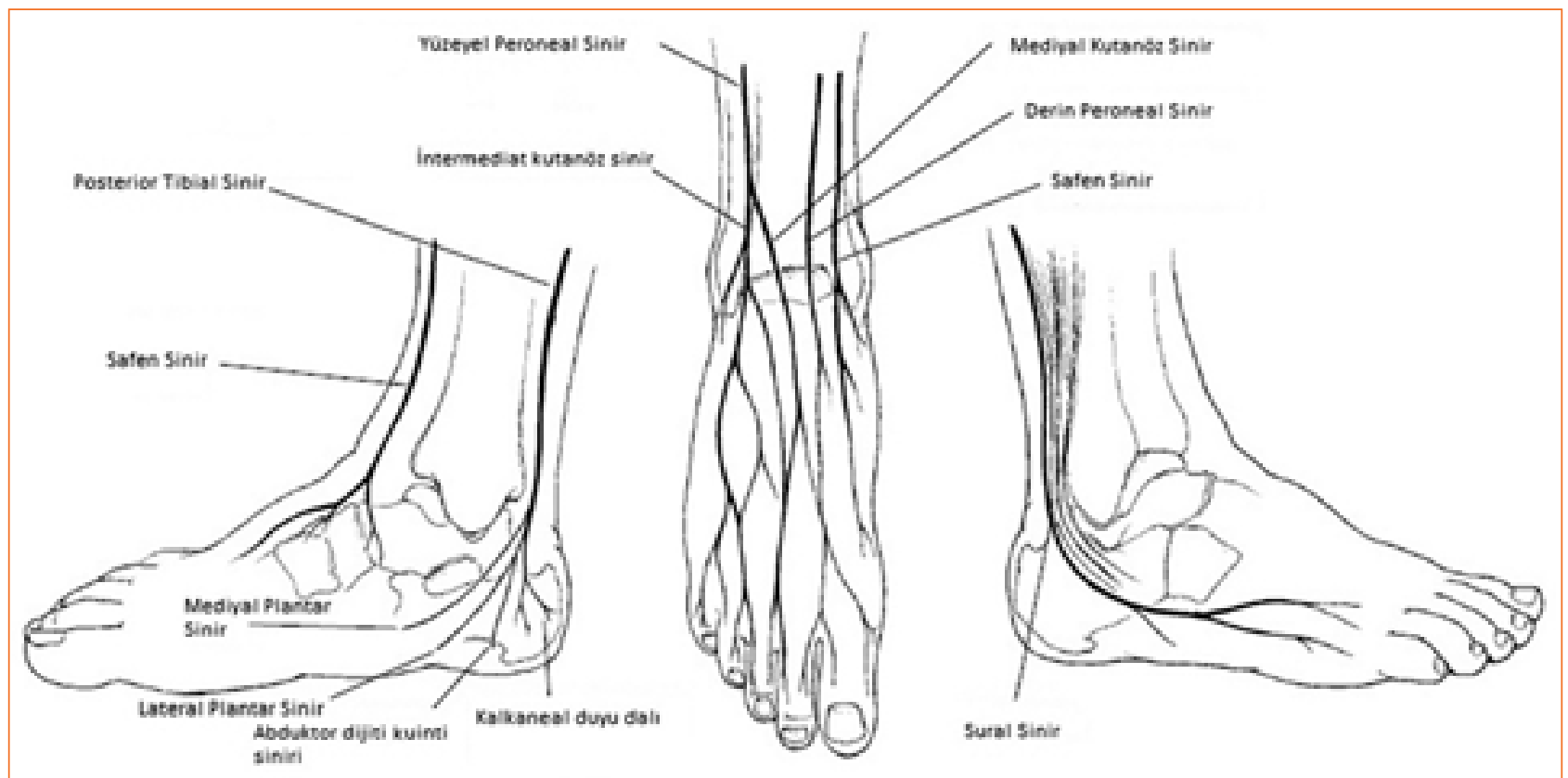

Şekil 1. Ayak bileğinden ayağa giren önemli sinirlerin anatomik görünümü. ${ }^{[2]}$

\section{PATOFIZYOLOJi}

Sinirin baskıya uğraması sırasında, sinir lifleri deforme olarak yerel iskemi oluşur ve damar geçirgenliği artar. Bu ödem, daha sonra endonöral çevreyi etkileyerek aksonal transportu bozar ve sinirin disfonksiyonuna yol açar. Eğer bası devam ederse, ödem ve disfonksiyona bağlı olarak, fibroblastlar siniri istila eder ve skar dokusu gelişimine yol açar. Bu skar dokusu, sinir fasiküllerinin eklem hareketleri sırasında birbirleri üzerinden normal kayma hareketini engeller. Doku basıncının 30 mm Hg'ye kadar çıkması, parestezi ve sinir iletisinde gecikmeye yol açar. Bu basıncın $60 \mathrm{~mm}$ Hg'ye çıkması ise sinir iletisini tamamen bloke eder. ${ }^{[3]}$

\section{SINIFLAMA}

Sinir basısı, hem süreye hem de şiddete bağıı olarak, karakteristik semptomatolojisi olan evrelerle ilerler. Hafif ve kısa süreli basılar, uyku sırasında olduğu gibi, aksonoplazmik akımın yavaşlamasına yol açar. Bası kalktığında, her şey normale döner. Ağır, akut basılarda, miyelin kılıfın kademeli invajinasyonu mikroskopta görülebilir. Bası kronik hale gelirse, segmenter demiyelinizasyon oluşur ve aksiyon potansiyellerinin ilerlemesine engel olarak, distalde Wallerian dejenerasyona yol açar. ${ }^{[4]}$

Sinir basısında üç klinik evre tanımlanmıştır. Evre I'de, özellikle geceleri oluşan kesintili parestezi dönemleri ve duyu kayıpları vardır. Evre II'de, sinir basısının devam etmesi sonucu, gün içinde geçmeyen daha ağır ve sürekli semptomlar vardır (parestezi, keçeleşme vb.). Evre III'te ise sinir mikro-sirkülasyonu ve ödemi, segmenter demiyelinizasyon dahil, önemli yapısal değişikliklere yol açar. Bu durumda, bası ortadan kalksa bile bulgular kalıcı olur. ${ }^{[3]}$ Evre I basılar, genellikle medikal ve breysleme ile tedavi edilirken, Evre II ve III'te cerrahi girişimler uygulanır.

\section{TARSAL TÜNEL SENDROMU}

Tarsal tünel sendromu (TTS), posterior tibial sinir veya dallarının (mediyal plantar, lateral plantar ve kalkaneal sinirler), ayak bileğinin mediyalinde, fleksör retinakulumun altında, fibro-osseöz tünelde sıkışması sonucu ortaya çıkan bir tuzak nöropatidir. Posterior tibial sinirin dekompresyonu, ilk olarak Keck ${ }^{[5]}$ tarafindan 1962 yılında bildirilmiş, aynı yıl Lam ${ }^{[6]}$ tarafından sendrom tanımlanmıştır.

Tarsal tünel tuzaklanması, proksimal ve distal sendromlara ayrılabilir. Burada, proksimal sendrom tibial sinirin bütününün basısını, distal sendrom ise terminal dallardan bir veya daha fazlasının basısını tanımlamaktadır. ${ }^{[7]}$ Çoğunlukla sinirin dalları tünel içinde yer aldığından, tünel içi bası nedenleri gibi, ayağın fasyal planları da terminal dalları sıkıştırabilir. Tünel dışındaki distal tuzaklanmalar içerisinde ise, mediyal plantar sinir basısı (Koşucu ayağı) ve lateral plantar sinirin 1. dalının tuzaklanması (Baxter nöropatisi) vardır. 


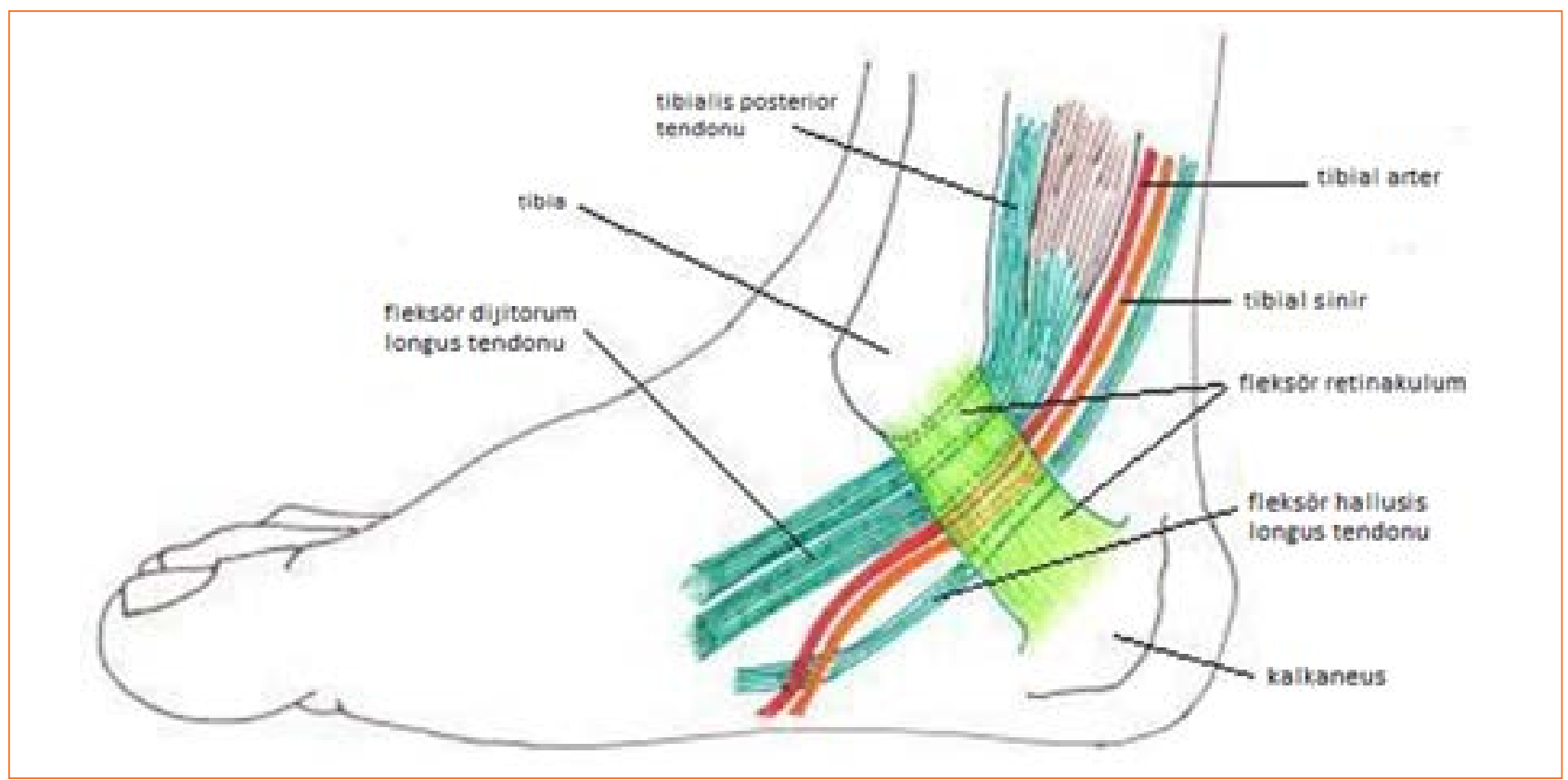

Şekil 2. Tarsal tünel anatomik komşulukları ve tibialis posterior sinirinin dalları.

\section{PROKSIMAL TTS}

Tibialis posterior siniri, en sık tarsal tünel içerisinde sıkışır. Tarsal tünelin ön duvarını tibia, lateral duvarını talus ve kalkaneus, çatısını da fleksör retinakulum oluşturur (Şekil 2).

Sıkışma nedenleri Tablo 1'de görülmektedir. Bunlar arasında en sık rastlanan, variköz genişlemelerdir.

\section{Klinik ve Tanı}

TTS, beşinci ve altıncı dekatlarda ve kadınlarda daha çok görülür. ${ }^{[9]}$ Semptomlar diffüz veya sınırlandırılmış olabilir. TTS'nin klinik bulguları, posterior tibial sinirin dallarının tuzaklanma yerine göre farklılık gösterebilir. Genelde ayağın plantar kısmına sınırlı ağrı veya parestezi ile ortaya çıkar. Tibial sinir ayağın tabanını innerve ettiğinden, semptomlar genellikle sadece topuğa sınırlı kalmayarak, ayak tabanına doğru da yayılır. Ağrı, parestezi ve uyuşma, en sık görülen semptom üçlüsüdür. ${ }^{[10]}$ Hastalar, ayağın plantar yüzeyinde ve parmaklarda iyi lokalize edilemeyen yanıcı bir ağrı ve paresteziden şikayet ederler. Tipik olarak, ağrı, yük taşıma aktiviteleri boyunca ve sonrasında kötüleşir, dinlenme sonrası düzelir.

\section{Fizik Muayene}

Ayak, herhangi bir deformite varlığı açısından muayene edilmelidir. Tibial sinir ve dallarının seyrettiği bölgelerde yer kaplayan lezyon açısından, herhangi bir kalınlaşma veya şişlik olup olmadığına bakılmalıdır. Ayak bileği, subtalar eklem ve transvers tarsal eklemlerin hareket açıklığı belirlenmelidir. En erken belirti, ayağın plantar kısmında iki nokta diskriminasyonu duyusunun azalmasıdır; ${ }^{[6]}$ hastalığın ilerlemesi ile, tutulan sinirin dermatomunda hipoestezi ortaya çıkar. Motor değerlendirme, parmakların, özellikle de ayağın

Tablo 1. Proksimal tarsal tünel sendromu nedenleri ${ }^{[8]}$

\begin{tabular}{ll}
\hline İçsel & Dışsal \\
\hline Variköz genişlemeler & Direkt travma \\
Gangliyon & Ayakkabı sıkması \\
Perinöral Fibroz & Ardayak deformiteleri \\
Lipom & Venöz konjesyon \\
Tenosinovit & Sistemik inflamatuvar artropati \\
Nörilemmoma & Diyabet \\
Ekzostoz & Cerrahi sonrası skar dokusu \\
Hipertrofik fleksör retinakulum & \\
Aksesuvar kaslar (soleus vb.) & \\
Hızlı kilo alma & \\
Sıvı retansiyonu &
\end{tabular}


intrensek kaslarındaki güçsüzlügüne işaret eden 4. ve 5. parmakların plantar fleksiyonu ile yapılır. Motor güçsüzlük, kronik ve ağır olgularda yaygın bir bulgudur. ileri evrelerde, abduktor hallusis veya abduktor dijiti minimi kasında atrofi gözlenebilir. TTS'nin objektif fizik muayene bulguları, tibial sinir kompresyonu veya gerilimini arttırarak semptomların ortaya çıkarılması ile bulunabilir.

Tinel işareti, tibial sinire mediyal malleol posteriorunda basınç uygulanması ile ortaya çıkan ağrıdır ve özellikli bir bulgudur; bacağın proksimaline doğru yayılım gösterebilir. Ayak bileğini maksimal dorsifleksiyona veya ayağı eversiyona getirmekle, tibial sinir üzerindeki gerilim arttırılarak semptomlar ortaya çıkarılabilir. Ayak ve ayak bileğinin nötral immobilizasyonu, posterior tibial sinir üzerindeki basıncı azaltıp, tarsal tünel kompartmanının hacmini olabildiğince arttırarak, semptomları azaltabilir ${ }^{[10]}$

\section{Görüntüleme}

TTS düşünülen olgularda direkt grafı ile hastanın ayak yapısı, kırık, kemik kitleleri, osteofitler ve subtalar koalisyon değerlendirilebilir. Yük vererek çekilen radyografiler ile, ayak ve ayak bileğine ait deformiteler değerlendirilebilir. ${ }^{[7]}$

Manyetik rezonans (MR) görüntüleme ve ultrasonografi (US), şüphelenilen olgularda tarsal tüneldeki yumuşak doku lezyonları ve diğer yer kaplayan lezyonları ayırt etmede yararlı olabilir (Şekil 3 ve 4). Bunlar ayrıca, fleksör tenosinovit ve ossifiye olmayan subtalar eklem koalisyonlarını değerlendirmede de yararlıdır. ${ }^{[7]}$ MR ile, ayak ve ayak bileği üç vertikal düzlemde değerlendirilebilir ve herhangi bir lezyon varsa, boyutu ve tibial sinir ile ilişkisi saptanabilir. Başarısız TTS cerrahisinde, yetersiz dekompresyon düşünülüyorsa MR ile tarsal tünel incelenebilir. Diyagnostik ultrasonografi ile, gangliyon, variköz venler, lipomlar, tenosivonit ve talokalkenal koalisyon belirlenebilir.

\section{Elektrodiyagnostik Çalışmalar}

Elektrodiyagnostik çalışmalar, sinir fonksiyonunu değerlendirir ve motor, duyusal ve mikst (birleşik) sinir testlerini içerir. TTS'de, mediyal ve lateral plantar sinir iletimlerinde uzamış latanslar ve abduktor hallusis longus ile abduktor dijiti minimi kaslarında posterior tibial sinir uyarımı ile elde edilen kas aksiyon potansiyellerinde azalma görülebilir. Özellikle erken evrelerde, normal motor cevaplar TTS'yi dışlayamaz; patoloji sadece duyu lifleri ile sınırlı olabilir. ${ }^{[1]}$ Mikst motor ve duyusal sinir iletim çalışmaları, tek başına duyusal sinir iletim çalışmalarına göre, erken değişiklikleri saptamada daha duyarlıdır. Anormal duyu iletim hızı ve anormal mikst duyu ve motor aksiyon potansiyelleri, TTS için duyarlılığı ve özgüllüğü arttırır. Elektrodiyagnostik çalışmada, tibial sinir, tarsal tünelin proksimali ve diğer alt ekstremite de incelenerek, etiyolojide "double crush" fenomeni ve periferal polinöropati dışlanmalıdır. İntrensek ayak kaslarının elektromiyografi (EMG) ile incelenmesi dikkatlice yapılmalıdır; yanlış pozitif sonuçlar olabilir. Üst ekstremitede yapılan elektrofizyolojik çalışmaların aksine, ayak deformitesi, deri değişiklikleri ve ödem gibi faktörler nedeniyle, alt ekstremitelerdeki çalışmalarda motor ve duyusal cevapları elde etmek zor olabilir. ${ }^{[11]}$ Mann ve Baxter ise, ayakta ağrı ve parestezi, pozitif Tinel işareti ve pozitif elektrodiyagnostik çalışma üçlüsü mevcutsa, TTS tanısının konulmasını önermiştir. Bu algoritmaya göre, eğer bu üçlünün her üç bileşeni de varsa, hastada TTS vardır; eğer sadece iki bulgu varsa, hastada olası TTS vardır ve dikkatlice incelenmelidir. Sadece bir bulgu varsa, hastada TTS yoktur ve diğer tanılar açısından değerlendirilmelidir. ${ }^{[12]}$

\section{Tedavi}

TTS tedavisi, konservatif ve cerrahi yöntemlerle yapılabilir. Akut olgular dışında, konservatif tedavi yeterli sürede uygulandıktan sonra cerrahi yapılması önerilmektedir. ${ }^{[12]}$

\section{Konservatif Tedavi}

Konservatif tedavide istirahat, immobilizasyon, ortezler, oral steroid olmayan anti-inflamatuvar ilaçlar, lokal kortikosteroid enjeksiyonları, fizyoterapi ve kilo kaybı önerilir. İmmobilizasyon için, ayak - ayak bileği ortezleri kullanılır. Eğer fleksibl bir ayak deformitesi mevcutsa, ayağı nötral pozisyonda tutacak bir ortez etkili olabilir. Fleksibl valgus deformitesi olan topukta, mediyal longitudinal ark destekleri ve mediyal topuk kamaları başarılı sonuçlar vermektedir. Lateral topuk kamalar, fleksibl varus topukları etkili olarak tedavi eder; bu olgularda mediyal ark desteklerinden kaçınılmalıdır. Dorsifleksiyonla semptomları artan hastalarda, 1 inçlik topuk desteği, tibial sinir üzerindeki gerilimi azaltarak semptomların iyileşmesine yardım eder. İntrensek ayak kaslarını, fleksör dijitorum longus, fleksör hallusis longus ve tibialis posterior kaslarını güçlendirme egzersizleri, mediyal longitudinal arkı desteklemek ve ayağı nötral pozisyonda stabilize etmeye yardımcı olmak için önerilir. Nöral mobilizasyon, yumuşak doku mobilitesini iyileştirmek için kullanılır. ${ }^{[13]}$

\section{Cerrahi Tedavi}

Konservatif tedavinin yetersiz kaldığı olgularda, cerrahi planlanabilir. ${ }^{[13]}$ Tarsal tünelde yer kaplayan 

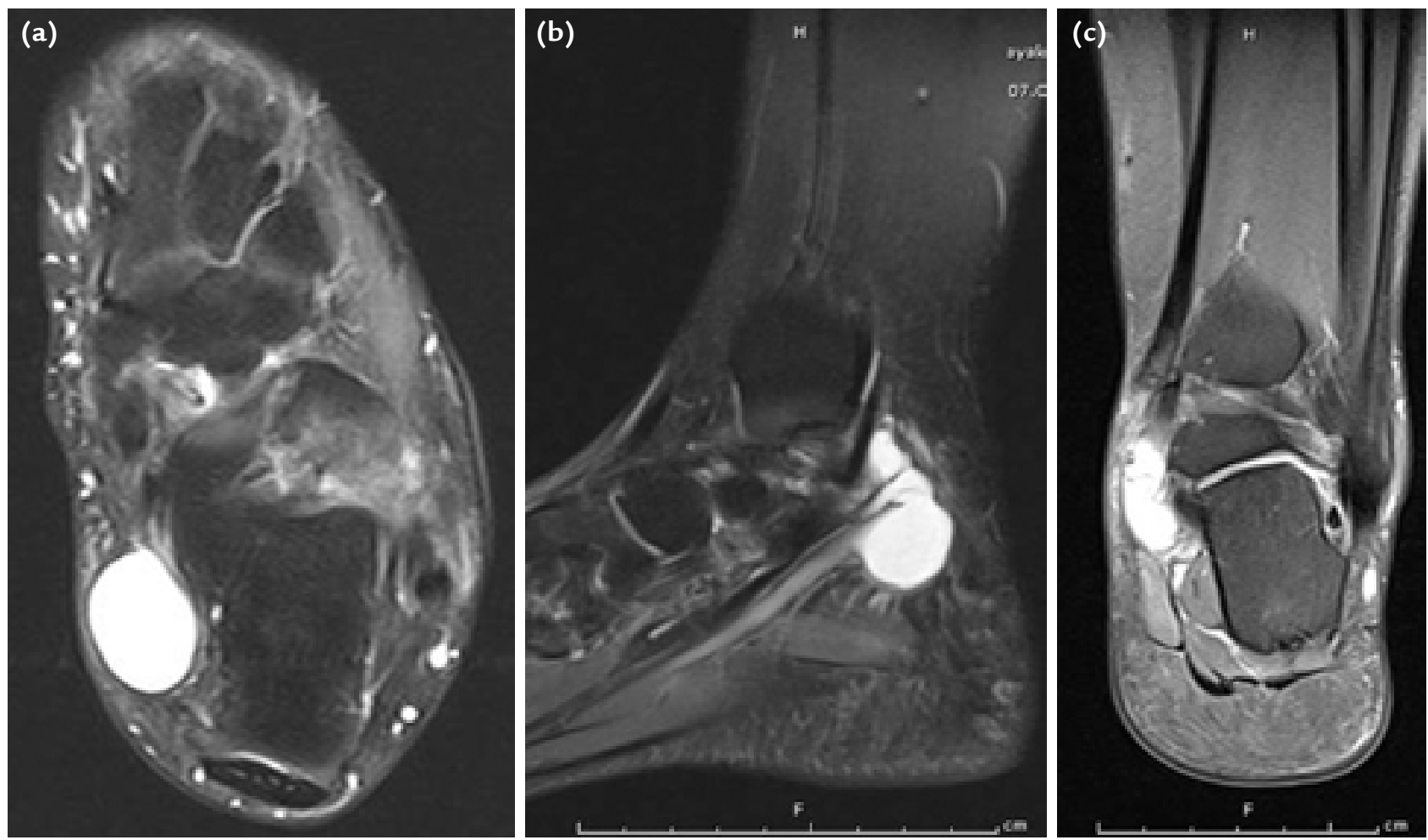

Şekil 3. a-c. MR T2 sekans aksiyel (a), sagittal (b) ve koronal (c) kesitlerde, tarsal tünelde gangliyon görülüyor.

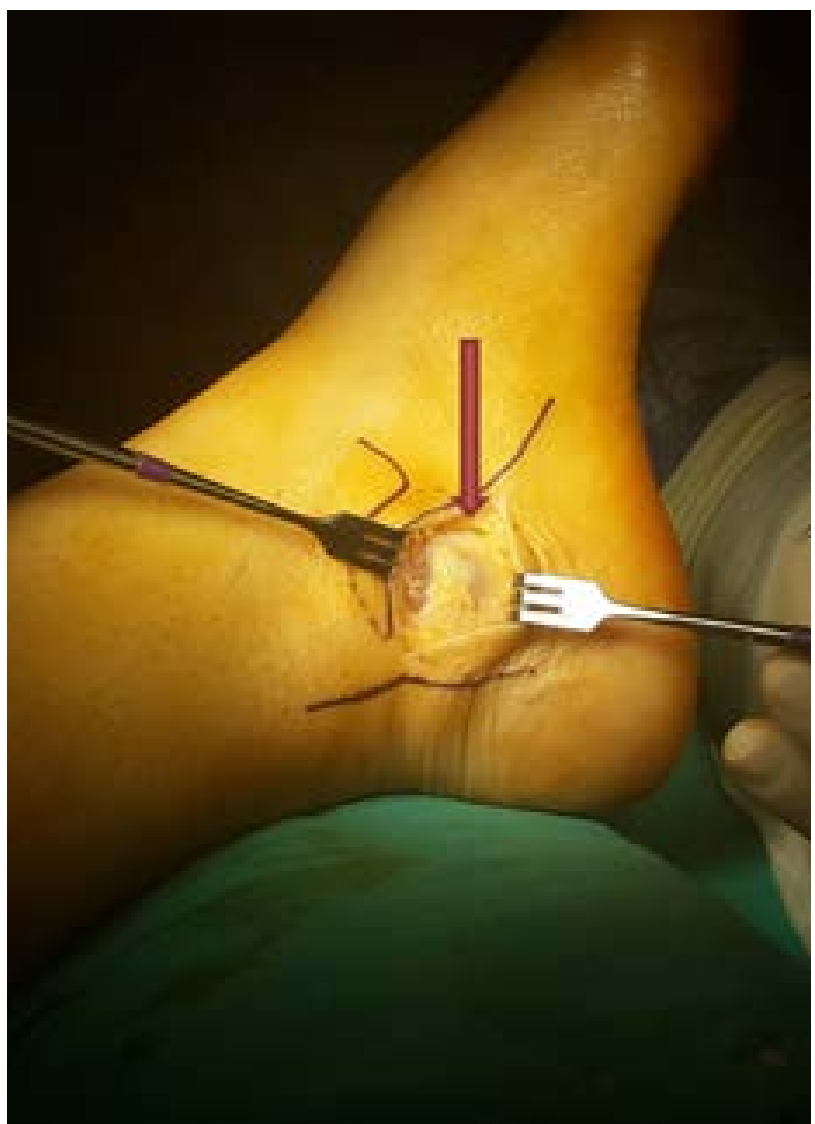

Şekil 4. Aynı hastanın (Şekil 3) ameliyat sırasındaki görüntüsü. lezyonu olan olgularda, cerrahi olmayan yöntemlerin herhangi bir anlamlı etkisi olmadığı saptanmıştır. ${ }^{[2]}$ Cimino'nun ${ }^{[14]}$ derlemesine göre, ortezleme ile fleksibl deformitesi olan hastaların \%34'ünde başarı elde edilirken, spontan rezolüsyon veya kortikosteroid enjeksiyonu \%24'ünde sonuç vermiştir. Cerrahi tedavi, fleksör retinakulumun serbestleştirilmesini; mediyal ve lateral plantar sinirlerin olabildiğince distalden nörolizini ve herhangi bir fraktür veya yer kaplayan lezyona müdahaleyi içerir.

Cerrahi tedavide, tüm fleksör retinakulum gevşetilmelidir. Yetersiz gevşetmenin ameliyat sonrası ağrıya yol açtığı gösterilmiştir. ${ }^{[12]}$ Aynı zamanda, mediyal plantar, lateral plantar ve kalkaneal sinirlerin de gevşetilmesi önerilmiştir. ${ }^{[2,12]}$ Cerrahide diğer önemli faktörler, basının nedeni ve cerrahinin zamanlamasıdır. Eğer yer kaplayan lezyon nedeniyle cerrahi yapılıyorsa, bu durumda sonuçlar daha yüz güldürücüdür. Semptom süreleri 1 yıldan az olan hastaların sonuçları, daha uzun olanlardan daha iyi bulunmuştur. Komplikasyonları arasında; inkomplet gevşetmeye bağlı semptomların devam etmesi, skar dokusu gelişimi, yara komplikasyonu, iyatrojenik nörovasküler yaralanma sayılabilir. ${ }^{[15]}$ 


\section{MEDIYAL PLANTAR SINIR TUZAKLANMASI (KOŞUCU AYAĞI)}

Mediyal plantar sinir, abduktor hallusisin kalkaneus ve naviküler kemikteki orijini ile fasyası arasında, abduktor hallusis kasının gövdesi ile Henry düğümü arasında veya mediyal intermusküler septumdan geçişi sırasında basıya uğrar. ${ }^{[16]}$

\section{Klinik}

Hastalarda, egzersiz sırasında ayağın mediyal plantar yüzünde ağrı oluşur. Ağrı, genellikle distalde 1., 2. ve 3. parmakların plantar yüzeyine ve proksimalde de topuk ve ayak bileğinin mediyaline yayılabilir. Ardayak valgusu olan uzun mesafe koşucularında daha fazla görülür. ${ }^{[1]}$

\section{Fizik Muayene}

Fizik muayenede, naviküler kemik çıkıntısı üzerinde pozitifTinel bulgusu, mediyal ayak arkı, topuk ve 1.-3. parmaklarda diestezi görülebilir. Hastalarda ardayak valgusu ve pes planus görülebilir; ayakkabılarının dıştan bası yapıp yapmadığına bakılmalıdır (Sert tabanlık var $\mathrm{m}$ ??).

\section{Görüntüleme}

Direkt radyografilerde, kemik anomalileri ve deformitelerine bakılır. MR'de, yer kaplayan lezyonlar ile etkilenen kasların denervasyon ödemine bakılır. ${ }^{[16]}$

\section{Tedavi}

Başlangıçta, proksimal tarsal tünel benzeri bir tedavi uygulanır. Başarısız olması durumunda, abduktor hallusis fasyası, kalkaneustaki orijininden Henry dügüumüne kadar cerrahi olarak gevşetilmelidir. Gevşetme proksimalde fleksör retinakuluma kadar uzatılarak tibial sinir eklenirse, tünel içerisinde sıkışma ihtimali de göz önüne alınmış olur.

\section{BAXTER NÖROPATISI}

Lateral plantar sinirin 1. dalının tuzaklanması, ilk olarak Baxter ve Thigpen tarfindan tanımlanmıştır. ${ }^{[18]}$ Tipik olarak abduktor hallusis ve kuadratus plantae kasları arasında sıkışırsa da, fleksör dijitorum brevis kası ile kalkaneus arasında sıkıştığı da bildirilmiştir. ${ }^{[18]}$

Etiyolojileri arasında; koşucularda sinirin gerilmesi, kas hipertrofileri, kemik çıkıntılar, plantar fasya orijinli bursit ve inflamasyonlar yer alır. ${ }^{[19]}$

\section{Klinik}

Lateral plantar sinirin 1. dalının tuzaklanması, plantar fasiitle aynı bölgede kronik mediyal topuk ağrısı olarak karşımıza çıkar. Ancak, plantar fasiitden daha proksimal ve mediyalde olup, aktivite ve ayak eversiyon ve abduksiyonu ile artar. Ağrı, mediyalde ayak bileğine veya distal ve lateralde ayağın plantarı kısmına yayılabilir. Genelde parestezi ve güçsüzlük yoktur.

\section{Fizik Muayene}

Fizik muayenede en sık, abduktor hallusisin derininde, sinir trasesi üzerinde hassasiyet görülür. Bu bölgenin palpasyonu, proksimal veya mediyale ağrının yayılmasına yol açar.

\section{Görüntüleme}

Daha ileri görüntüleme yöntemleri, ancak kemik yapıda bir sorun olması veya yapısal bozukluklarda işe yarayacaktır. Elektrodiyagnostik çalışmalar, basının kesin yerini saptamada yardımcı olabilir. ${ }^{[8]}$ MR'de, abduktor dijiti miniminin atrofisi, bası bulgusu olarak görülür. Ancak, normalde de görülen bu bulgu aldatıcı olabilir. ${ }^{[17]}$

Cerrahi tedavi genellikle gereklidir. Önerilen tedavi, önce abduktor hallusis kasının proksimal derin fasyasının gevşetilmesi ile nörolizdir. Daha sonra ise, sinir distale doğru takip edilerek, mediyal plantar fasya veya fleksör dijitorum brevisin kalkaneusa yapışma yerinin gevşetilmesidir. Bu bölgede bir kemik çıkıntı nedeniyle sıkışma varsa, bunun küçük bir kısmının çıkarılmasının yeterli olduğu bildirilmiştir. ${ }^{[18]}$

\section{SOLEAL ASKI (SLING) SENDROMU}

Soleal askı sendromu, tibial sinirin, bacağın proksimalinde soleus kasının orijininde fibröz bir askıya sıkışması ile oluşur (Şekil 5). Hastalar, baldır ağrısı veya tarsal tünel benzeri semptomlardan yakınırlar. Bu hastalarda, başarısız tarsal tünel cerrahisi yapılmış olma öyküsü de olabilir. Bu nokta, ayırııı tanıda göz önünde tutulmalıdır.

\section{Fizik Muayene}

Fizik muayenede, popliteal katlanma noktasının yaklaşık $9 \mathrm{~cm}$ altında, baldırın posteriorunda soleal askı seviyesinde palpasyonla ağrı ortaya çıkar. Tanının konmasında bu nokta önemlidir.

\section{Klinik}

Hastalarda, tibial sinirin dağılım alanında duyusal değişiklikler olabilir. Özellikle fleksör hallusis longusta güçsüzlük olabilir. Bu seviyede sinirin derinde yer alması nedeniyle, sinir ileti çalışmaları ve EMG'nin işe yaramadığı gösterilmiştir. Bu tetkikler, yalnızca duyusal periferik nöropati ve daha distal veya proksimal sinir 


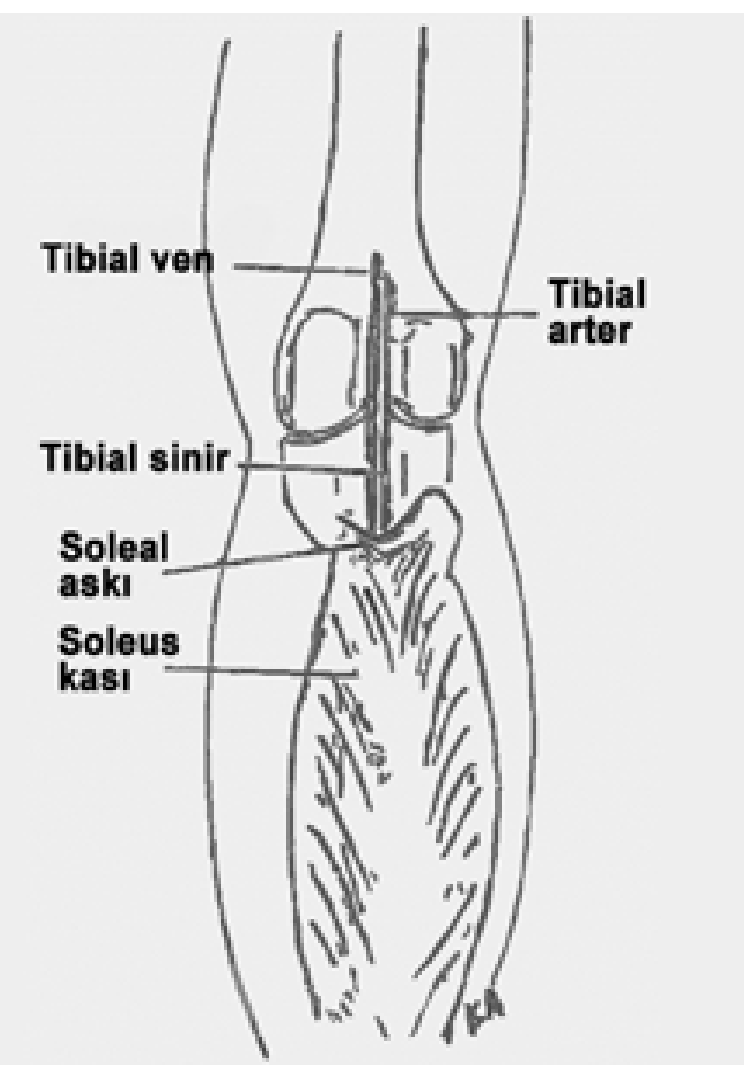

Şekil 5. Soleal askı anatomisi. ${ }^{[8]}$

basısını göstermeye yarar. Tanının kesinleştirilmesinde yeni 3 Tesla MR ve manyetik rezonans nörografi protokolleri yararlı olabilir. ${ }^{[17]}$

\section{Tedavi}

Konservatif tedavide, ağrı uyandıran aktivitelerden, sıkıştıran bot veya giysilerden kaçınma önerilir. Antiinflamatuvar ilaçlar ve sinir modülatörlerinin de yararı olabilir. Konservatif tedavinin başarısız olması durumunda, açık gevşetme ile sinirin serbestleştirilmesinin, komplikasyonsuz başarılı sonuçları bildirilmiştir. ${ }^{[8]}$

\section{MORTON NÖROMASI}

Morton nöroması, intermetatarsal bağın distal kenarında, sıklıkla 3. web aralığında, daha az olarak da 2. web aralığında görülen, interdijital sinirin bir tuzak nöropatisidir. Bu nedenle, 2. web aralığında görülmesi durumunda, 2. metatarsofalengeal eklemin instabilitesi akla gelmelidir. Nöromanın kendisi, perinöral fibrozis ve dejeneratif değişikliklerden oluşan selim bir lezyondur. Sıkışmanın nerede olduğu bilinmemektedir. Bazı hekimler, birincil sıkışma yerinin intermetatarsal bağ olduğuna inanırken, diğerleri, metatars başlarının ve/veya onları çevreleyen yumuşak dokuların basıya neden olduğuna inanmaktadırlar. ${ }^{[19,20]}$

\section{Klinik}

Kadınlarda, muhtemelen önü dar ayakkabı giymeye bağlı, daha çok görülmektedir. Hastalar, etkilenen web aralığında genellikle yanma veya elektriklenme ve parestezi yanı sıra, yürürken ayaklarının altında bir bilye varlığını tarif ederler.

\section{Fizik Muayene}

Fizik muayenede, hastanın ağrıyı duyduğu noktaya plantar bölgede metatars başları arasından direkt baskı (pozitif Mulder bulgusu) veya hastaya metatars başııın $2 \mathrm{~cm}$ proksimaline ve intermetatarsal bağın plantarına izole lidokain enjeksiyonu ile ağrının geçirilmesi testleri uygulanabilir. ${ }^{[21]}$

\section{Görüntüleme}

Birçok hastada klinik tanı konmasına karşın, tanı için direkt grafiler, US veya MR kullanılabilir. Direkt grafide, osteonekroz, stres kırığı veya MTF eklem artrozu gösterilebilir. US ve MR görüntüleme, nöromayı büyük çoğunlukla saptarsa da, semptomatoloji ile uyumlu değildir. Bu yöntemlerle nöroma saptanan hastaların çoğu, klinik olarak asemptomatikdir. Bu nedenle, tanısal testler, yalnızca klinik şüphe varlığında geçerli kabul edilmelidir. ${ }^{[17]}$

\section{Tedavi}

Konservatif tedavi seçenekleri arasında; kişiye özel ayakkabı ve tabanlıklar, metatarsal pedler, anti-inflamatuvar ilaçlar ve enjeksiyonlar sayılabilir. Kortikosteroid enjeksiyonlarının çelişkili sonuçları vardır. Kısa dönemde iyi sonuçları olmalarına karşın, uzun dönemde etkileri devam etmemektedir. Aynı zamanda, enjeksiyon tekrarları plantar plate ve MTP eklem kapsülüne de zarar verebilmektedir. Bir diğer tedavi yöntemi olan seri alkol enjeksiyonları, çevre dokuya zarar vermesi ve sonuçlarının güvenilmez olması nedeniyle kullanılmamaktadır.

Cerrahi tedavide en sık kullanılan yöntem, dorsal yaklaşımla, primer lezyonlarda nöromanın eksizyonudur (Şekil 6 ve 7). Mükemmel sonuçlar bildirilmesine karşın, iyileşme oranları \%51-93 arasında değişmektedir. Giannini ve arkadaşları, ağrı, maksimum yürüme mesafesi, duyu ve ayakkabı içerisine yardımcı araç kullanma ihtiyacı parametrelerine dayanan bir ölçümleme yöntemi geliştirmiştir. ${ }^{[22]} \mathrm{Bu}$ ölçümleme ile çok iyi sonuçlar bildirmelerine karşın, Womack ve arkadaşları, aynı yöntemle başarısız sonuçların daha yüksek olduğunu bildirmişlerdir. ${ }^{[23]}$ 

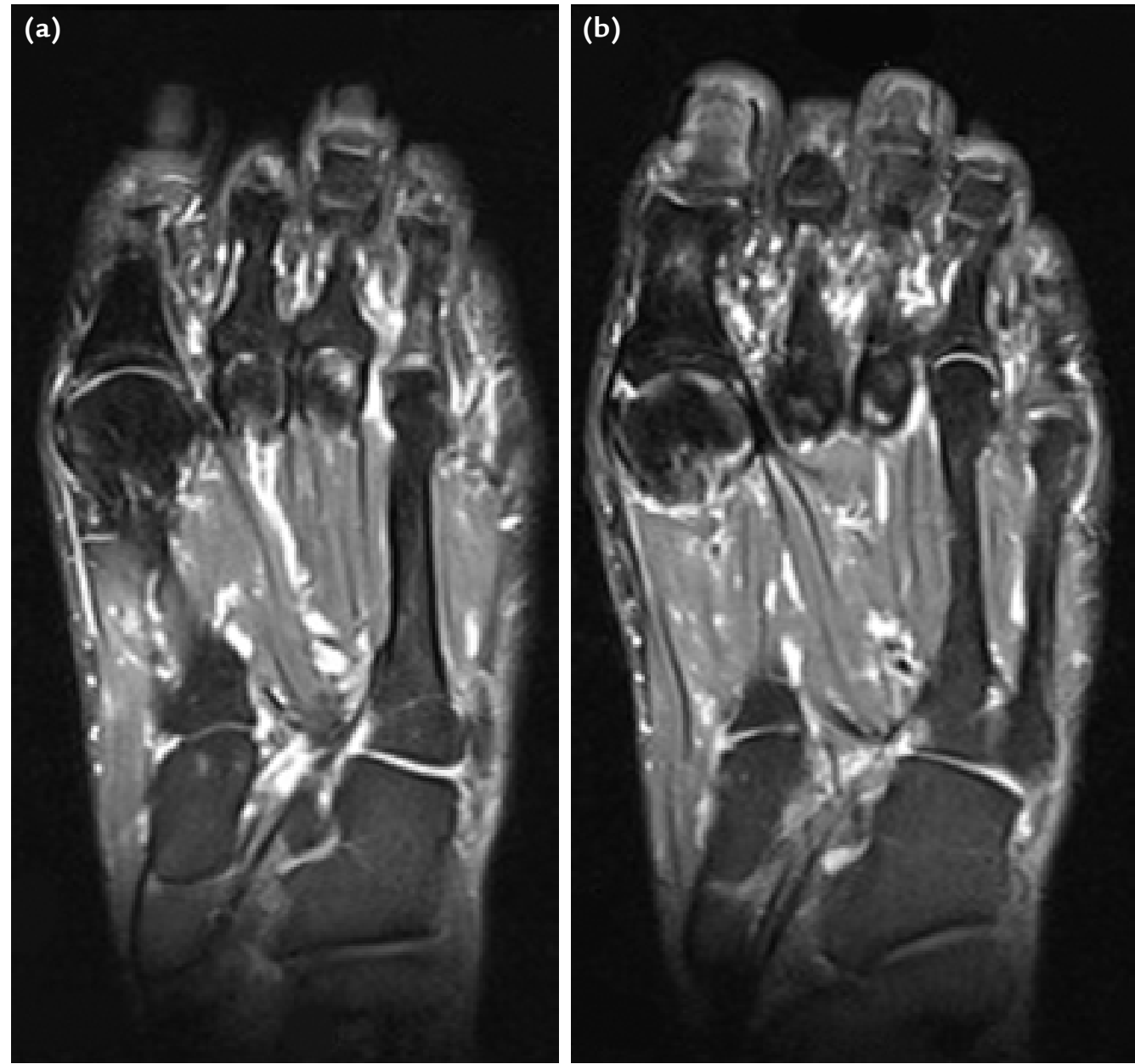

Şekil 6. a, b. Morton nörinomu T2 sekans aksiyel kesitler.
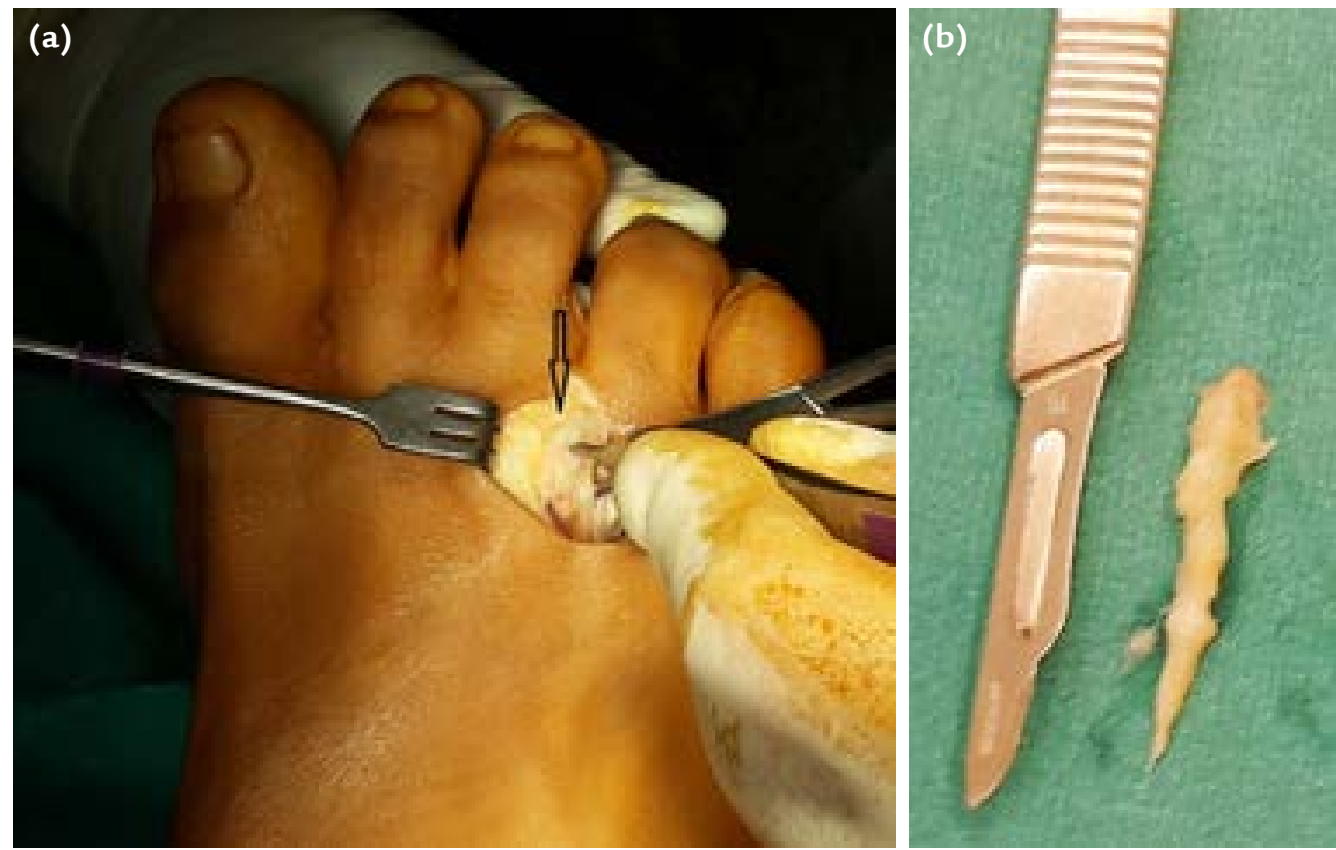

Şekil 7. a, b. Aynı hastanın (Şekil 6) ameliyat sırasındaki görüntüsü (a) ve eksizyonel parça (b). 
En sık rastlanan komplikasyon, yetersiz sinir dokusu rezeksiyonu veya yanlış dokunun (lumbrikal tendon veya dijital sinir) çıkarılmasına bağlı olarak ağrının tekrarlamasıdır. Bu komplikasyondan kaçınmak için bazı çalışmacılar, nöromanın açık veya endoskopik yolla dekompresyonunu önermişlerdir. Bu yolla, \%78-96 oranında düzelme sağlandığı bildirilmiştir. Villas ve arkadaşları, hibrid bir yaklaşımla, eğer cerrahi sırasında sinirin kalınlaştığı gösterilirse rezeksiyonunu, aksi bir durumda ise transvers metatarsal bağın gevşetilmesini önermişlerdir.

\section{YÜZEYEL PERONEAL SINIR TUZAKLANMASI}

Yüzeyel peroneal sinirin (YPS) tuzaklanması, kronik bacak ağrısının nadir rastlanan bir nedenidir. YPS, ortak peroneal sinirin dallarından birisidir ve bacağın lateral kompartmanı boyunca inerek, peroneus longus ve brevis kaslarını innerve eder. Ancak, anatomik çalışmalarda, sinirin \%14-17 oranında anterior kompartmanda seyrettiği gösterilmiştir. ${ }^{[24]}$ Sinir, bacağın derin fasyasını delerek, lateral malleolun ucunun yaklaşık 12,5 cm proksimalinde cilt altına çıkar. Bu sırada, fasyal tünel içerisinde kalınlaşma, defekt ve kas herniyasyonu veya lipom gibi yumuşak doku kitlesi ile tuzaklanabilir. Aynı zamanda lateral bağ yetmezliği veya fonksiyonel ayak bileği instabilitesi olan sporcularda, traksiyon yaralanmasına bağlı olarak da gelişebilir. ${ }^{[8]}$

\section{Klinik}

Hastaların çoğu, bacağın alt dış kısmında aktiviteye bağlı ağrı ve ayağın dorsal ve lateral kısmında diestezi tarif ederler. Semptomlar, ayağın eversiyonu ve plantar fleksiyonu ile birlikte, sinirin derin fasyayı delerek çıktığı yere perküsyonla tekrar ortaya çıkarılabilir.

\section{Fizik Muayene ve Görüntüleme}

Tanı, hastanın öyküsü ve fizik muayenesi ile konur. Sinir iletisi ve EMG çalışmaları güvenilir olmayıp, tedavinin sürecini etkilemez. Ayırıcı tanıda, kronik egzersize bağlı kompartman sendromu akılda tutulmalı ve gerekirse kompartman basıncı ölçülmelidir. Tanıyı güçlendirmek için, en hassas olan noktaya lokal anestezi yapılarak ağrının geçip geçmediği kontrol edilebilir.

\section{Tedavi}

Tedavinin başlangıcında, kompresyona yol açabilecek bütün dış faktörlerin ortadan kaldırılması ve siniri geren tüm instabilitelerin tespiti gerekir. Cerrahi nadiren gerekli olur. Ancak, eğer gerekirse, özellikle kronik egzersize bağ ı kompartman sendromlu hastalarda, sinirin çıkış noktasının etrafındaki fasyanın dekompresyonu yapılır. Anterior ve lateral kompartmanın distal fasyal kısmının ve iki kompartman arasındaki septumun gevşetilmesi önerilmiştir. ${ }^{[24]}$ Cerrahi tedavi sonuçları değişken olup, olgu serileri şeklinde olsa da, konservatif tedavinin başarısız kaldığı yerde cerrahinin uygulanması önerilmektedir.

\section{ANTERIOR TARSAL TÜNEL SENDROMU}

Derin peroneal sinir (DPS), anterior tibial tendon ve $E H L$ arasında, ayak bileği mortisinin $5 \mathrm{~cm}$ üzerinde seyreder. Ayak bileğinin yaklaşı $1 \mathrm{~cm}$ üzerinde superior ekstansör retinakulumun altında sinir, mediyal ve lateral dallarına ayrılır. Lateral dalı inferior ekstansör retinakuluma doğru derinleşerek, ekstansör dijitorum brevisin motor dalını ve ayak bileği eklemini ve tarsal lateral eklemlerin duyusunu verir. Mediyal dal, inferior ekstansör retinakulumun altından dorsalis pedis arteri ile seyrederek, 1 . web aralığının duyusunu verir. DPS veya dallarının basısı, anterior tarsal tünelden geçişleri sırasında olabilir. Anterior tarsal tünelin yüzeyel kısmında inferior ekstansör retinakulum, derin kısmında ise talonaviküler eklem kapsülü vardır. Bu tünelden geçen diğer yapılar ise; dorsalis pedis arteri, veni, EHL tendonu, tibialis anterior ekstansör dijitorum longus ve peroneus tertius tendonlarıdır (Şekil 8).

\section{Klinik}

DPS lateral dal kompresyonu olan hastalar, tipik olarak ayağın dorsal lateral tarsometatarsal eklemlerinin bölgesine yayılan ağrı tarif ederler. Mediyal sinir tuzaklanması, 1 . Web aralığında ağrı ve/veya uyuşmadan yakınırlar.

\section{Fizik Muayene}

Fizik muayenede, tüm DPS fibula başının arkasından 1. web aralığına kadar muayene edilmelidir. Basının esas noktası, lokal anestezi ile test enjeksiyonu yapılarak bulunabilir.

\section{Görüntüleme}

Direkt radyoloji, anterior tarsal tünel sendromunun en sık nedenleri travma ve talonaviküler eklem etrafındaki osteofitler olduğu için, çok önemlidir. Eğer yer kaplayıcı lezyon düşünülüyorsa, MR yapılabilir. EMG'de, ekstansör dijitorum brevis kasına giden sinirde latens görülürse, inferior ekstansör retinakulumun proksimalinde sıkışmayı göstereceği için değerlidir.

\section{Tedavi}

Konservatif tedavi içerisinde; dış bası etkenlerinin ortadan kaldırılması, ayak bileğinde tüm laksitelerin stabilizasyonu, fizik tedavi, breysleme, ayakkabı 


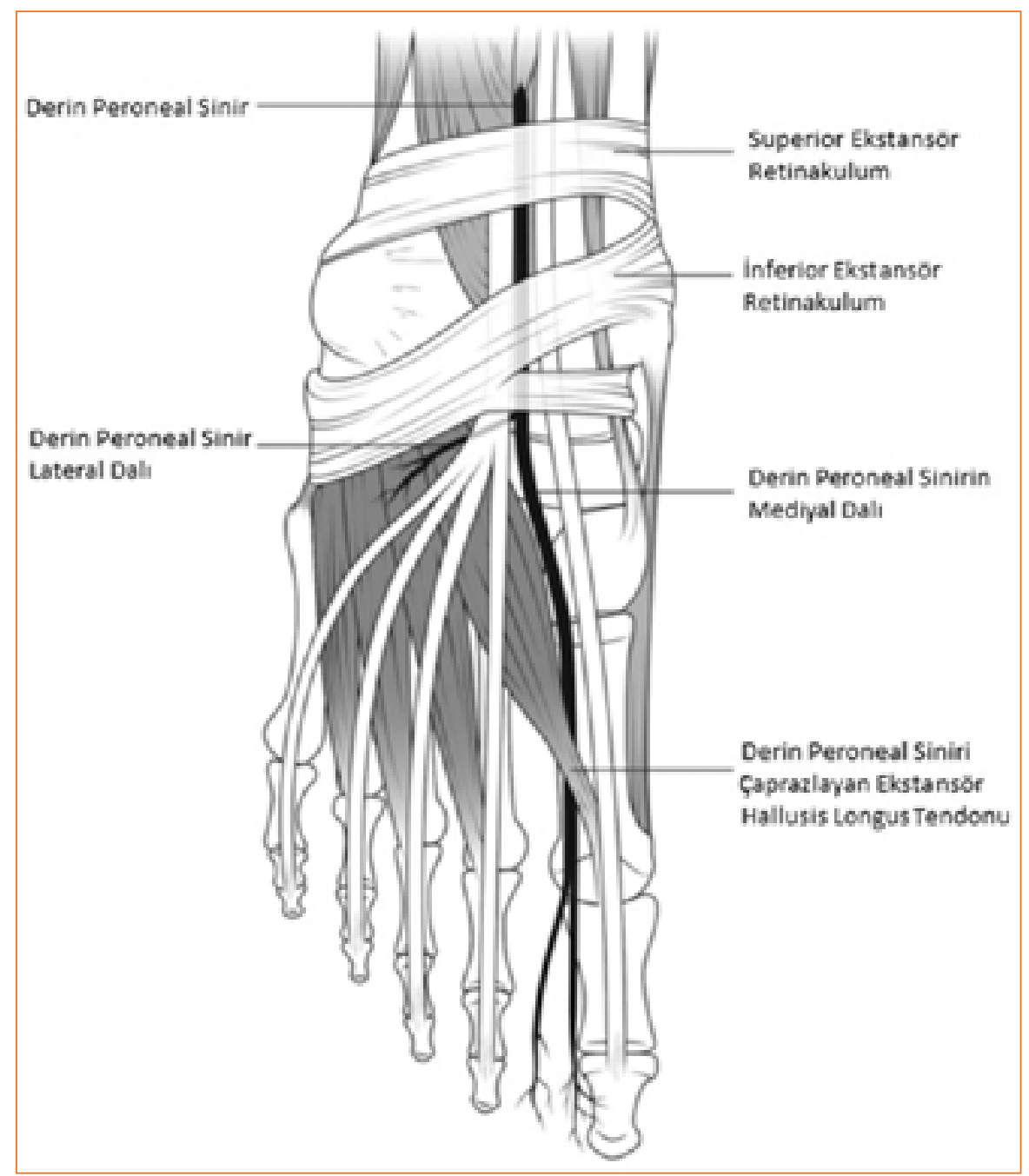

Şekil 8. Derin peroneal sinir ve dalları. ${ }^{[8]}$

modifikasyonu ve anti-inflamatuvar ilaçlar ile enflamasyonun giderilmesi yer alır. Cerrahi tedavi, tekrarlayan kronik olgularda sinirin aşırı disseksiyonundan kaçınılarak yapılabilir. Ekstansör retinakulum, yalnızca sinir gevşetilecek kadar açılır. Tam açılırsa, tendonların pörtlemesine yol açabilir. Ayak bileği veya talonaviküler eklemin dorsal kenarında, etrafindaki tüm osteofitler alınmalıdır. Eğer sinire ekstansör hallusis brevis kası basıyorsa, kısmi rezeksiyonu ve EHL'ye transferi yapılabilir. ${ }^{[25]}$

\section{SURAL SINIR}

Sural sinir bacak, ayak bileği ve ayağın herhangi bir yerinde, nadirde olsa tuzaklanabilir. En sık, ayak bileğinin lateralinde kalkaneusta ve 5. metatarsta sıkışır. Sıkışma, sıklıkla travma ve/veya cerrahi girişimlere, kemik büyümelerine, yumuşak doku skarlarına veya instabiliteye ikincil gelişir. Ancak, travma olmaksızın, proksimal Aşil tendonunun lateral kenarında derin pozisyondan yüzeyelleştiği bir noktada, fibröz bir köprüye bağlı olarak da basıya uğrayabilir. ${ }^{[26]}$

\section{Klinik}

Hastalar, bacağın posterolateralinde, ayak bileğinin lateralinde veya ayağın lateralinde ağrı, yanma, uyuşma veya ağrı tarif ederler.

\section{Fizik Muayene}

Fizik muayenede, sinirin trasesi boyunca Tinel bulgusu ve ayağın plantar fleksiyonu ve inversiyonu sırasında semptomların şiddetlenmesi görülebilir. Ancak, genç sporcularda Tinel bulgusu negatif olabilir ve ağrı da, 
özellikle Aşil tendonunun muskülotendinöz bileşkesinde, bacağın posterolateralinde görülür.

\section{Görüntüleme}

Direkt grafilerde, basıya neden olabilecek kemik oluşumsal veya siniri gerebilecek yapısal anormallikler görülebilir. Sinire baskı yapabilecek yumuşak doku kitleleri veya yer kaplayan lezyonları ortaya çıkarmak için, MR görüntüleme kullanılabilir. Modern sinir ileti çalışma protokolleri, lumbosakral sinir kökü patolojilerini ortaya rahatlıkla çıkarabilir.

\section{Tedavi}

Tedavinin başarısı, etken faktörlerin ve bası noktalarının doğru saptanmasına bağlıdır. Basıya yol açabilecek periferik ödemler ve instabiliteler öncelikle ele alınmalı, bunlarla birlikte dar ayakkabılar veya semptomları oluşturabilecek egzersiz tipleri gibi dış faktörlere de dikkat edilmelidir. Buna ek olarak, etiyolojide posttravmatik veya ameliyat sonrası koşullar rol oynuyorsa, yazarlar, 3-6 ay arası gözlem, duyarsızlaştırma ve sinir kaydırma tekniklerinin ameliyat öncesi kullanıması gerektiğini düşünmektedirler. Diğer konservatif tedavi yöntemleri arasında; anti-inflamatuvar ilaçlar, sinir iletisini etkileyen ilaçlar, ve steroid enjeksiyonları vardır. Cerrahide, kemik anomalileri, deformiteler veya eklem instabiliteleri hedef alınır. Eğer etken bulunamadıysa, basının tam yeri saptanmaya çalışılmalıdır. Bundan sonra, sinir gevşetmesi veya sinir rezeksiyonu uygulanabilir.

\section{SAFEN SINIR}

Sural sinir gibi, safen sinir tuzaklanmaları da nadir görülür. Tipik olarak, bası daha proksimalde olmasına karşın, hastalar ayak ve ayak bileğinde ağrı ve uyuşma ile başvururlar. Distal tutulumlar, daha sıklıkla travma veya cerrahiye ikincil görülmektedir. ${ }^{[1]}$

\section{Görüntüleme}

Tanının genellikle klinik olarak konmasına karşın, direkt grafi, bilgisayarlı tomografi ve/veya MR çekilerek, kemik veya yumuşak doku bası odakları görülebilir. Sinir ileti çalışmaları güvenilir değildir. Asemptomatik hastalarda, safen sinir \%25 olasılıkla gösterilememektedir. Ancak, diğer sinir basılarında olduğu gibi, daha yukarıda femoral sinir veya lomber kök basısını ortadan kaldırabilir.

Cerrahi girişimler, konservatif tedavi denenip başarısız kalırsa yapılabilir. Cerrah, dekompresyon, nöroliz veya nörektomiyi tercih eder. Nörektominin kalıcı duyu kusuruna yol açacağı unutulmamalıdır.

\section{SONUÇ}

Ayak ve ayak bileği çevresi tuzak nöropatileri, ender görülen hastalıklar olup, özellikle konservatif tedaviye yanıt vermeyen ağrılarda akılda tutulmalıdır. Ortopedi hekimi, bu hastaların tedavisini yapabilmek için, ilgili sinir anatomisini iyi bilmeli, çoğunluğu konservatif tedaviye yanıt veren bu nöropatilerin etkenlerini tanımalıdır. Cerrahi girişimlere geçmeden önce, ayırıcı tanıda özellikle inflamatuvar hastalıklar mutlaka akılda tutulmalıdır. Sinir ileti çalışmaları ve görüntüleme yöntemleri, daha çok bu sendromların diğer nedenlerini dışlamak için kullanılır. Klinik öykü ve fizik muayene bulguları, genellikle tanıda yol göstericidir.

\section{KAYNAKLAR}

1. Flanigan RM, DiGiovanni BF. Peripheral nerve entrapments of the lower leg, ankle, and foot. Foot Ankle Clin 2011;16(2):255-74. CrossRef

2. Beskin JL. Nerve Entrapment Syndromes of the Foot and Ankle. J Am Acad Orthop Surg 1997;5(5):261-9.

3. Lundborg G, Dahlin LB. Anatomy, function, and pathophysiology of peripheral nerves and nerve compression. Hand Clin 1996;12(2):185-93.

4. Gelberman RH, Eaton RG, Urbaniak JR. Peripheral nerve compression. Instr Course Lect 1994;43:31-53.

5. Keck $C$. The tarsal tunnel syndrome. J Bone Joint Surg 1962;44:80-82.

6. LamSJ.Atarsal-tunnelsyndrome. Lancet 1962;2(7270):1354-5.

7. Lopez-Ben R. Imaging of nerve entrapment in the foot and ankle. Foot Ankle Clin 2011;16(2):213-24. CrossRef

8. Pomeroy G, Wilton J, Anthony S. Entrapment neuropathy about the foot and ankle: an update. J Am Acad Orthop Surg 2015;23(1):58-66. CrossRef

9. Alshami AM, Souvlis T, Coppieters MW. A review of plantar heel pain of neural origin: differential diagnosis and management. Man Ther 2008;13(2):103-11.

10. Labib SA, Gould JS, Rodriguez-del-Rio FA, Lyman S. Heel pain triad (HPT): the combination of plantar fasciitis, posterior tibial tendon dysfunction and tarsal tunnel syndrome. Foot Ankle Int 2002;23(3):212-20.

11. Patel AT, Gaines K, Malamut R, Park TA, Toro DR, Holland N; American Association of Neuromuscular and Electrodiagnostic Medicine. Usefulness of electrodiagnostic techniques in the evaluation of suspected tarsal tunnel syndrome: an evidence-based review. Muscle Nerve 2005;32(2):236-40.

12. Mann RA, Baxter DE. Diseases of the nerve. In: Mann RA, Coughlin MJ, editors. Surgery of the foot and ankle, vol. 1. 6th ed. St Louis (MO): Mosby-Year Book; 1993. p.554-8.

13. Uzunkulaoğlu A, İkbali Afşar S. Tarsal Tünel Sendromu. FTR Bil Der 2014;17:189-195.

14. Cimino WR. Tarsal tunnel syndrome: review of the literature. Foot Ankle 1990;11(1):47-52.

15. Pfeiffer WH, Cracchiolo A 3rd. Clinical results after tarsal tunnel decompression. J Bone Joint Surg Am 1994;76(8):1222-30.

16. Rask MR. Medial plantar neurapraxia (jogger's foot): report of 3 cases. Clin Orthop Relat Res 1978;(134):193-5. 
17. Donovan A, Rosenberg ZS, Cavalcanti CF. MR imaging of entrapment neuropathies of the lower extremity. Part 2. The knee, leg, ankle, and foot. Radiographics 2010;30(4):100119. CrossRef

18. Baxter DE, Thigpen CM. Heel pain -operative results. Foot Ankle 1984;5(1):16-25.

19. Lareau CR, Sawyer GA, Wang JH, DiGiovanni CW. Plantar and medial heel pain: diagnosis and management. J Am Acad Orthop Surg 2014;22(6):372-80. CrossRef

20. Kim JY, Choi JH, Park J, Wang J, Lee I. An anatomical study of Morton's interdigital neuroma: the relationship between the occurring site and the deep transverse metatarsal ligament (DTML). Foot Ankle Int 2007;28(9):1007-10.

21. Peters PG, Adams SB Jr, Schon LC. Interdigital neuralgia. Foot Ankle Clin 2011;16(2):305-15. CrossRef

22. Giannini S, Bacchini P, Ceccarelli F, Vannini F. Interdigital neuroma: clinical examination and histopathologic results in 63 cases treated with excision. Foot Ankle Int 2004;25(2):79-84.
23. Womack JW, Richardson DR, Murphy GA, Richardson EG, Ishikawa SN. Long-term evaluation of interdigital neuroma treated by surgical excision. Foot Ankle Int 2008;29(6):5747. CrossRef

24. Rosson GD, Dellon AL. Superficial peroneal nerve anatomic variability changes surgical technique. Clin Orthop Relat Res 2005;438:248-52.

25. Dellon AL, Aszmann OC. Treatment of superficial and deep peroneal neuromas by resection and translocation of the nerves into the anterolateral compartment. Foot Ankle Int 1998;19(5):300-3.

26. Yuebing L, Lederman RJ. Sural mononeuropathy: a report of 36 cases. Muscle Nerve 2014;49(3):443-5. CrossRef 